\title{
THE EFFECTS OF TONGUE PLATE AND TONGUE APPLIANCE ON MAXILLARY DEFICIENCY IN GROWING PATIENTS
}

\author{
Abdolreza Jamilian ${ }^{1 a^{*}}{ }^{(1)}$, Ludovica Nucci ${ }^{2 b}$, Ehsun Amini ${ }^{3 c}$, Mitra Toliat ${ }^{\text {1d }}$, Shima Bagherzadeh Hamedani ${ }^{4 e}$, \\ Felice Femiano ${ }^{2 f}(\mathbb{D}$ \\ 'Department of Orthodontics, Faculty of Dentistry, Cranio Maxillofacial Research Center, Tehran Medical Sciences, Islamic Azad University, Tehran, Iran \\ 2Multidisciplinary Department of Medical-Surgical and Dental Specialties, Dental School, University of Campania Luigi Vanvitelli, Naples, Italy \\ 3Department of Oral and Maxillofacial Surgery, Dental School, Shahid Beheshti University of Medical Sciences, Tehran, Iran \\ ${ }^{4}$ Clinical Division of Orthodontics, Faculty of Dentistry, Medical University of Vienna, Vienna, Austria
}

aDDS, MSc, PhD, Professor; e-mail: info@jamilian.net; ORCIDiD: https://orcid.org/0000-0002-8841-0447

bDDS, Undergraduate Dental Student; e-mail: ludovica.nucci@virgilio.it; ORCIDiD: https://orcid.org/0000-0002-7174-7596

'DDS, OMFS Resident; e-mail: Ehsun.amini@gmail.com

'DDS; e-mail:Toliatmitra@gmail.com

eDDS; e-mail: ajamilian@yahoo.com

fDDS, PhD, Professor; e-mail: felice.femiano@unicampania.it; ORCIDiD: https://orcid.org/0000-0001-9341-2490

\section{ABSTRACT}

d) https://doi.org/10.25241/stomaeduj.2020.7(4).art.4

Objectives The purpose of this randomized trial study was to compare the effects of tongue plate and tongue appliance in the treatment of Class III malocclusion with maxillary deficiency in growing patients. Material and Methods 40 patients (19 males, 21 females) with maxillary deficiency were selected. 20 patients (9 boys, 11 girls) with the mean age of $9.3 \pm 1.2$ were treated with tongue plate. 20 patients (10 boys, 10 girls) with the mean age of $10.1 \pm 0.7$ were treated by tongue appliance. Lateral cephalograms obtained at the beginning and end of the study were analyzed.

Results Paired t-tests and Wilcoxon test showed that SNA and ANB significantly increased in both groups. The Mann-Whitney test showed that there were no statistically significant differences between the two groups except for Jarabak ratio. Jarabak increased by $0.6 \pm 3.2^{\circ}$ in the tongue appliance group and it decreased $0.4 \pm 1.6^{\circ}$ in the tongue plate group $(p<0.03)$.

Conclusion Both treatment modalities were successful in moving the maxilla forward. The crib of the tongue appliance might bother the tongue and consequently parents are complaining about minor inflammation of the tongue. The smooth surface of the tongue plate might therefore confer some advantages to this system as compared to the tongue plate.

\section{KEYWORDS}

Class III Malocclusion; Tongue Plate; Growth Modification; Maxillary Deficiency; Tongue Appliance.

\section{INTRODUCTION}

Skeletal Class III malocclusion is characterized by mandibular prognathism, maxillary retrusion or a combination of both. Approximately, half of the skeletal Class III malocclusions are reported to result from maxillary deficiency[1].

A series of treatment approaches can be found in the literature regarding orthopedic treatment in Class III malocclusion with maxillary deficiency in growing patients. Delaire[2] developed the orthopedic face mask to stimulate maxillary growth. Reverse-pull headgear was also used to treat this discrepancy $[3,4]$. The use of ankylosed primary canines as anchorage for maxillary orthopedics is a viable alternative method[5,6]. Recently, tongue appliance[7-10], tongue plate[11,12], miniplates[13, 14], bone-anchored maxillary protraction[15-17],

(c) (1) () OPEN ACCESS This is an Open Access article under the CC BY-NC 4.0 license. Peer-Reviewed Article

Citation: Jamilian A, Nucci L, Amini E, Toliat M, Hamedani SB, Femiano F. The effects of tongue plate and tongue appliance on maxillary deficiency in growing patients. Stoma Edu J. 2020;7(4):259-267.

Received: August 07, 2020; Revised: August 24, 2020; Accepted: August 28, 2020; Published: September 01, 2020

*Corresponding author: Professor Abdolreza Jamilian, DDS, MSc, PhD, Department of Orthodontics, Faculty of Dentistry, Cranio Maxillofacial

Research Center, Tehran Medical Sciences, Islamic Azad University, Tehran, Iran

Tel./Fax: 0098-22052228; e-mail: info@jamilian.net

Copyright: $\odot 2020$ the Editorial Council for the Stomatology Edu Journal. 
ITable 1. Pre and post treatment measurements of the tongue plate and tongue appliance.

\begin{tabular}{|c|c|c|c|c|}
\hline $\begin{array}{l}\text { Cephalometric } \\
\text { measurement }\end{array}$ & Groups & $\begin{array}{l}\text { Pre treatment } \\
\text { Mean } \pm \text { SD }\end{array}$ & $\begin{array}{l}\text { Post treatment } \\
\text { Mean } \pm \text { SD }\end{array}$ & p value \\
\hline \multirow[t]{2}{*}{ SNA $^{\circ}$} & Tongue Plate & $76.0 \pm 1.7$ & $78.4 \pm 1.7$ & $0.001^{*}$ \\
\hline & Tongue Appliance & $75.9 \pm 2.8$ & $77.4 \pm 2.7$ & $0.001^{*}$ \\
\hline \multirow[t]{2}{*}{$\mathrm{SNB}^{\circ}$} & Tongue Plate & $76.9 \pm 1.8$ & $77.5 \pm 1.4$ & 0.08 \\
\hline & Tongue Appliance & $77.2 \pm 2.9$ & $77.2 \pm 2.9$ & 1 \\
\hline \multirow[t]{2}{*}{ ANB $^{\circ}$} & Tongue Plate & $-0.9 \pm 1.1$ & $0.7 \pm 1.6$ & $0.001^{*}$ \\
\hline & Tongue Appliance & $-1.4 \pm 1.7$ & $0.2 \pm 1.4$ & $0.001^{*}$ \\
\hline \multirow[t]{2}{*}{ U1 to $\mathrm{SN}^{\circ}$} & Tongue Plate & $99.9 \pm 6.1$ & $103.7 \pm 5.3$ & $0.02^{*}$ \\
\hline & Tongue Appliance & $98.6 \pm 6$ & $99.9 \pm 7.2$ & 0.3 \\
\hline \multirow[t]{2}{*}{ ANS-PNS (mm) } & Tongue Plate & $45.7 \pm 3.1$ & $47 \pm 3$ & $0.001^{*}$ \\
\hline & Tongue Appliance & $45.1 \pm 3.9$ & $45.7 \pm 3.5$ & $0.007^{*}$ \\
\hline \multirow[t]{2}{*}{ Palatal-SN ${ }^{\circ}$} & Tongue Plate & $10.9 \pm 3.4$ & $10.4 \pm 4.1$ & 0.2 \\
\hline & Tongue Appliance & $9.2 \pm 3$ & $8.4 \pm 2.8$ & 0.2 \\
\hline \multirow[t]{2}{*}{ GoGn (mm) } & Tongue Plate & $65 \pm 4$ & $66.9 \pm 3.8$ & $0.001^{*}$ \\
\hline & Tongue Appliance & $66.4 \pm 7.4$ & $67.5 \pm 8$ & 0.1 \\
\hline \multirow[t]{2}{*}{ Jarabak R. (\%) } & Tongue Plate & $61.7 \pm 3.7$ & $61.3 \pm 3.8$ & 0.3 \\
\hline & Tongue Appliance & $61.7 \pm 3$ & $62.3 \pm 4.4$ & 0.5 \\
\hline \multirow[t]{2}{*}{ U1 to Palatal ${ }^{\circ}$} & Tongue Plate & $108.7 \pm 11.4$ & $111.8 \pm 11.4$ & $0.03^{*}$ \\
\hline & Tongue Appliance & $107.8 \pm 6.3$ & $108.8 \pm 7.8$ & 0.6 \\
\hline \multirow[t]{2}{*}{ Inclination Angle } & Tongue Plate & $81.4 \pm 3.4$ & $83 \pm 4.3$ & $0.05^{*}$ \\
\hline & Tongue Appliance & $83.6 \pm 3.2$ & $85.9 \pm 5.8$ & 0.07 \\
\hline \multirow[t]{2}{*}{ GoGn-SN } & Tongue Plate & $35.9 \pm 5.4$ & $36.4 \pm 4.9$ & 0.3 \\
\hline & Tongue Appliance & $35.4 \pm 4.7$ & $34.4 \pm 6.3$ & 0.3 \\
\hline \multirow[t]{2}{*}{ IMPA $^{\circ}$} & Tongue Plate & $92.3 \pm 6.2$ & $87 \pm 6.5$ & $0.001^{*}$ \\
\hline & Tongue Appliance & $88.2 \pm 6.6$ & $83 \pm 5.5$ & $0.001^{*}$ \\
\hline
\end{tabular}

and miniscrew $[18,19]$ have also been used to treat maxillary deficiency. As known, the maxilla cannot be moved after growth cessation; therefore, the common belief is that the treatment of adult patients will eventually need surgery[20].

Both the tongue appliance and tongue plate have recently been introduced to literature and there is no previous comparison between the effects of the two; therefore, the aim of this study was to compare the effects of the tongue plate and tongue appliance in growing patients with class III malocclusion due to maxillary deficiency.

\section{MATERIALS AND METHODS}

In this retrospective study, the patient data were handled according to the requirements and recommendations of the Declaration of Helsinki. The ethical approval was obtained from SBUMS Local Research Ethics Committees. The informed written consent was obtained from the patient and a parent or guardian. A CONSORT diagram showing the flow of patients through the trial is provided in Fig1. Sixty-eight patients were enrolled in this research. 23 patients were excluded due to not meeting the inclusion criteria. Three of the patients in the tongue plate and 2 patients in the tongue appliance dropped out before final assessment. 40 patients (19 males, 21 females) with skeletal Class III malocclusion due to maxillary deficiency were selected. Considering the previous studies, a sample size of 40 patients was chosen for this study[21-23]. All subjects gave their informed written consent and met the following inclusion criteria:

1) Sella-Nasion-A (SNA) $\leq 80^{\circ}$, Sella-Nasion-B (SNB) $\leq$ $80^{\circ}$, A-Nasion-B (ANB) $\leq 0^{\circ}$

2) Class III molar relationship

3) No mandibular shift

4) Concave facial profile

5) Negative overjet

6) No congenital disease or endocrine disorders

7) No previous orthodontic treatment and surgical intervention.

An unstratified subject allocation sequence was generated by a computer program; random numbers were generated and their assignment was concealed from the clinician until the time of the appointment at which the appliance was to be placed. The treating clinician was blinded from the randomization procedure, but because of clear differences in appliance design, blinding was not possible during the treatment period. A table of 


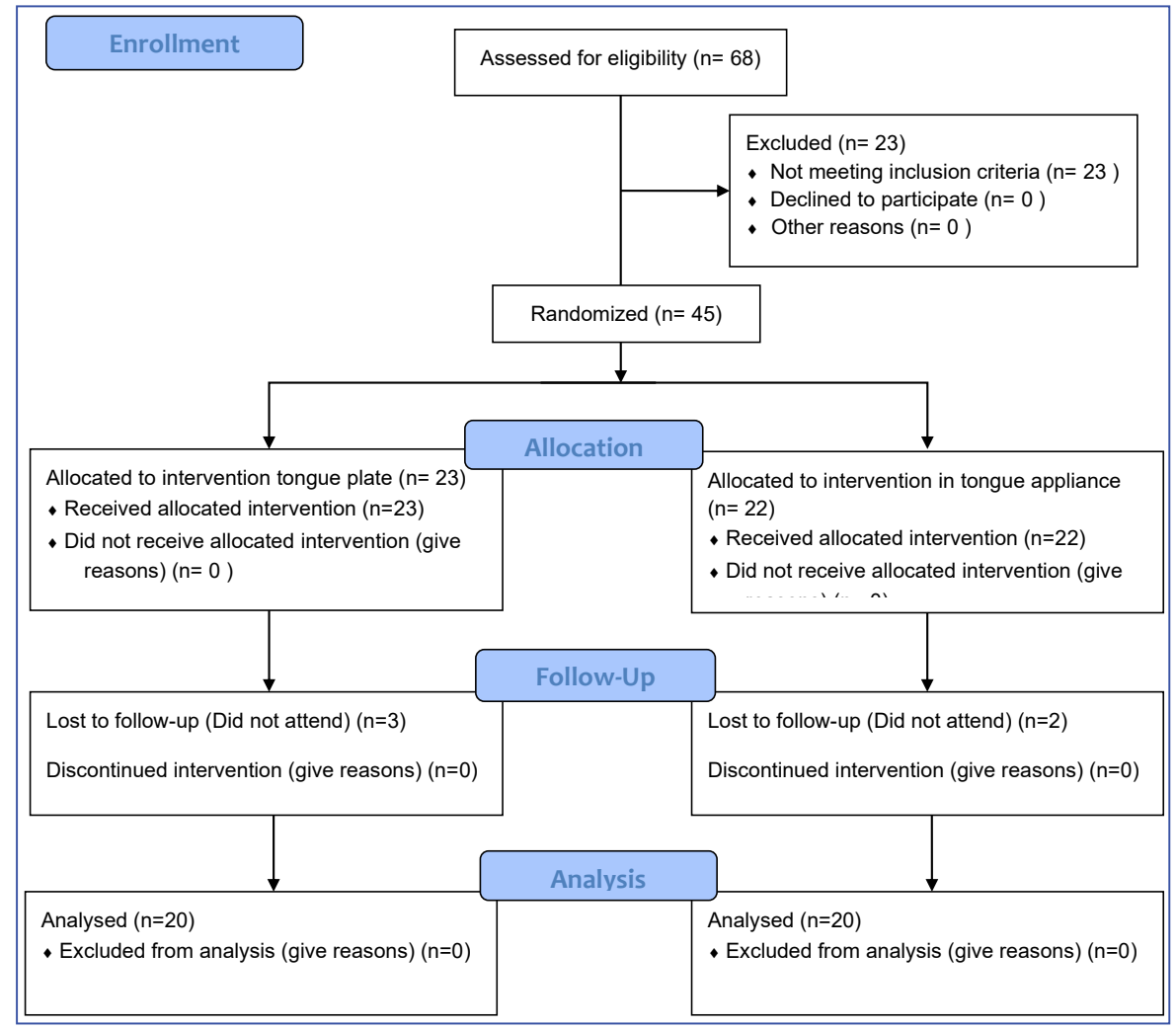

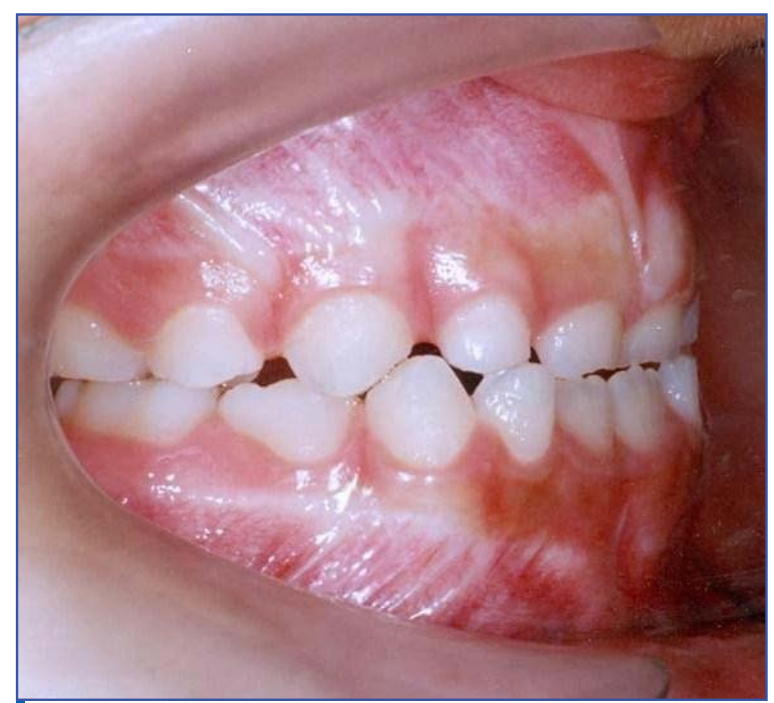

Figure 2. Right view of pretreatment of a tongue plate patient.

random numbers was used to divide the patients into two equal groups. A CONSORT diagram showing the flow of patients through the trial is provided in Fig. 1. The patients were randomly assigned to two equal groups using a standard random number table. The tongue appliance has some $C$ clasps on the upper permanent central or lateral incisors or deciduous canines. An acrylic plate was mounted posterior to the upper incisors. The patient was instructed to wear the appliance full-time except for eating, contact sports and tooth brushing. The active treatment time lasted for 24 months. The patient was examined and progress was observed after each monthly visit. Pre and post photographs and cephalometric images of one of the tongue plate patients can be seen in

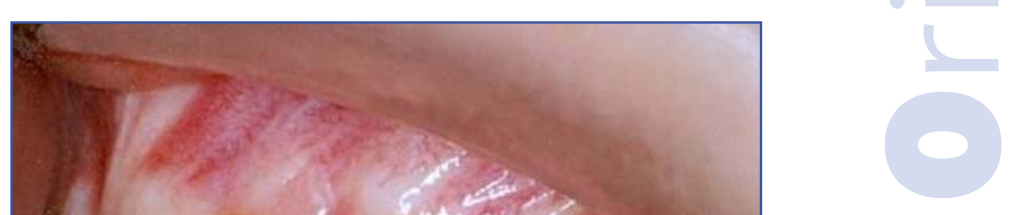

Figs. 2-8. 20 patients (10 boys, 10 girls) with the mean age of $10.1 \pm 0.7$ were treated by tongue appliance. A tightly fitting and well retained upper removable appliance was fabricated with Adams clasps on the upper first permanent molars and two $C$ clasps were placed on the upper permanent central or lateral incisors or deciduous canines. Long tongue cribs were placed in the inter-canine area in an effort to restrict the tongue. These cribs were long enough to cage the tongue and were adjusted to avoid traumatizing the floor of the mouth.

The patients were instructed to wear the appliance full-time except for eating, contact sports and tooth brushing. The active treatment time lasted for $17 \pm 3$ months. The patients were examined and progress 
Iable 2. Comparison of cephalometric changes between tongue plate and tongue appliance.

\begin{tabular}{|c|c|c|c|}
\hline $\begin{array}{l}\text { Cephalometric mea- } \\
\text { surement }\end{array}$ & $\begin{array}{c}\text { Tongue Plate } \\
\qquad \pm \text { SD }\end{array}$ & 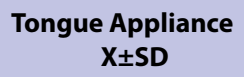 & p Value \\
\hline SNA $\left({ }^{\circ}\right)$ & $2.4 \pm 1.5$ & $1.5 \pm 1.4$ & 0.2 \\
\hline ANB $\left({ }^{\circ}\right)$ & $1.6 \pm 1$ & $1.6 \pm 1.6$ & 0.6 \\
\hline U1 to $\mathrm{SN}\left({ }^{\circ}\right)$ & $3.8 \pm 6.3$ & $1.3 \pm 5.5$ & 0.2 \\
\hline Palatal-SN $\left({ }^{\circ}\right)$ & $-0.5 \pm 3.4$ & $-0.8 \pm 2.9$ & 0.6 \\
\hline GoGn (mm) & $1.9 \pm 1.3$ & $1.1 \pm 1.5$ & 0.09 \\
\hline Jarabak R. (\%) & $-0.4 \pm 1.6$ & $0.6 \pm 3.2$ & 0.03 \\
\hline IMPA $\left({ }^{\circ}\right)$ & $-5.3 \pm 3$ & $-5.2 \pm 7.2$ & 0.7 \\
\hline
\end{tabular}

*Statistical significance was set at $\mathrm{p}<0.05$

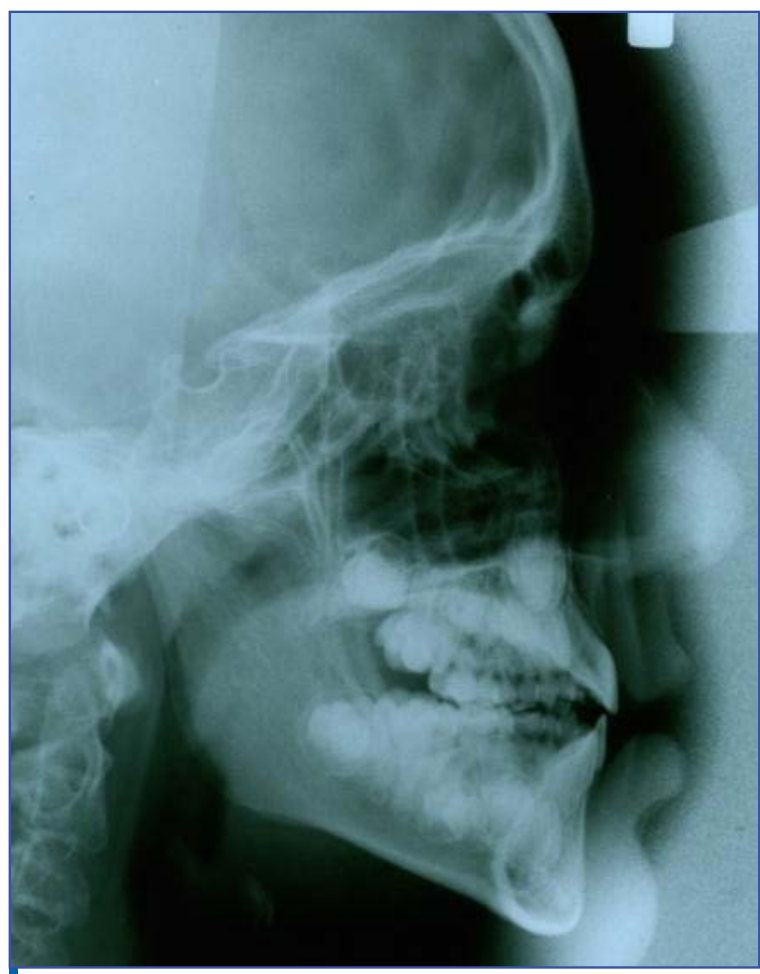

Figure 4. Pretreatment cephalometric of a patient with tongue plate.

was observed after each monthly visit. Pre and post photographs and cephalometric images of one of the tongue appliance patients can be seen in Figs. 9-14. Lateral cephalograms, OPGs, photos, and study casts of patients of both groups were taken before (T1) and after (T2) treatment.

SNA, SNB, ANB, GoGn-Sn (mandibular plane angle), Upper 1 to SN (angle between long axis upper central incisor and anterior cranial base), IMPA (angle between the long axis of the lower central incisor and mandibular plane), Nasolabial angle (the angle formed between the lines tangent to the columella and the upper lip vermillion and intersecting at

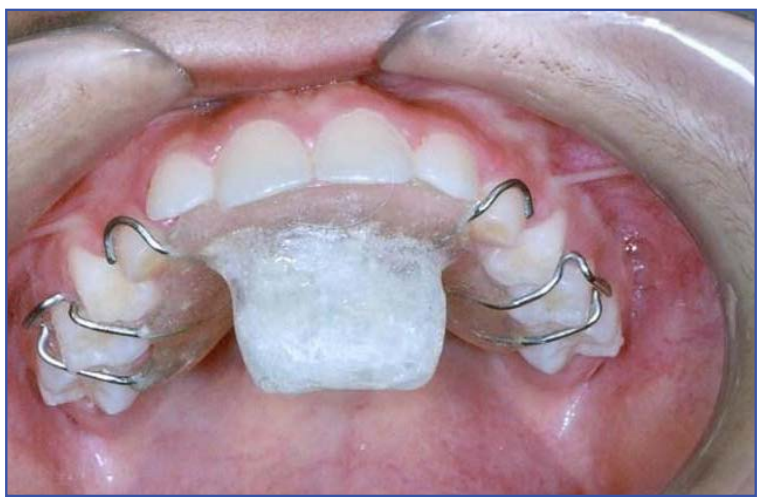

Figure 5. Tongue plate in situe.

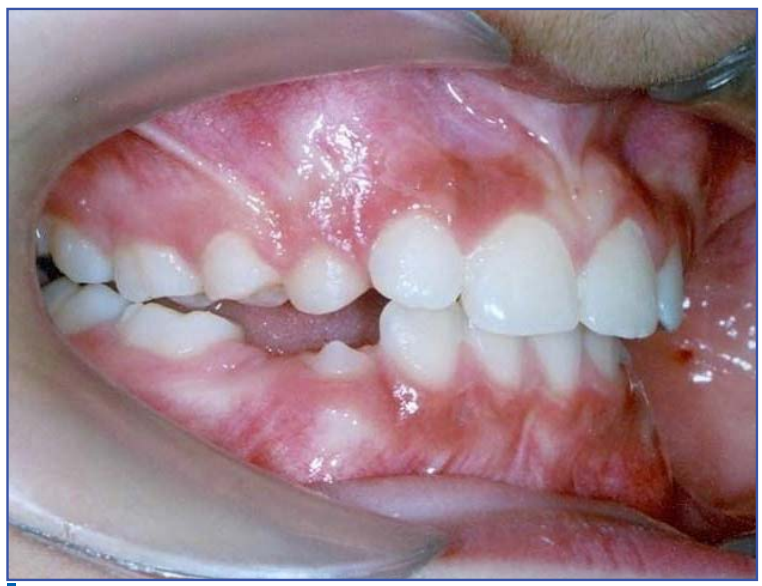

Figure 6. Right view of posttreatment of the same tongue plate patient.

the subnasale), inclination angle (the angle formed between a perpendicular line to soft tissue nasion and the palatal plane), and Jarabak ratio (the ratio between the posterior and anterior face heights; $\mathrm{S}-\mathrm{Go} / \mathrm{N}-\mathrm{Me}$ ) of each patient were measured before and after treatment.

The reliability of the measurements was determined by randomly selecting 16 cephalograms at the beginning and end of the treatment from each group. They were traced twice on two separate occasions 


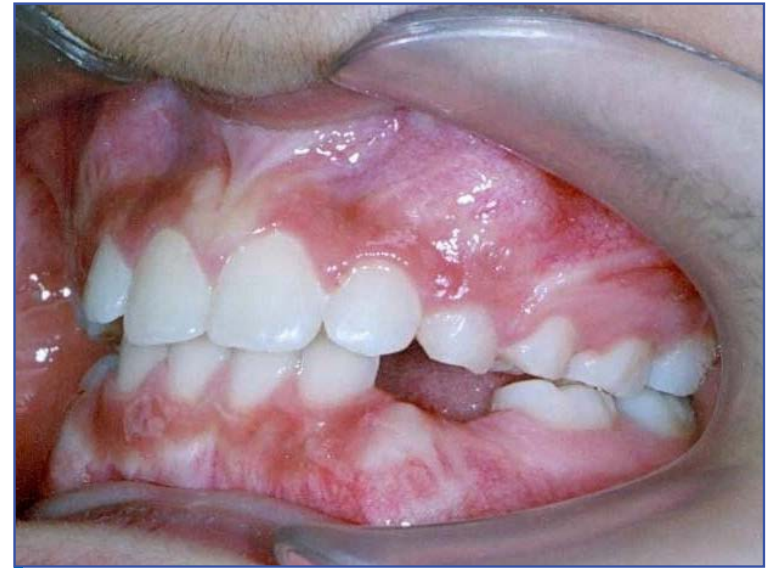

Figure 7. Left view of posttreatment of the same tongue plate patient.

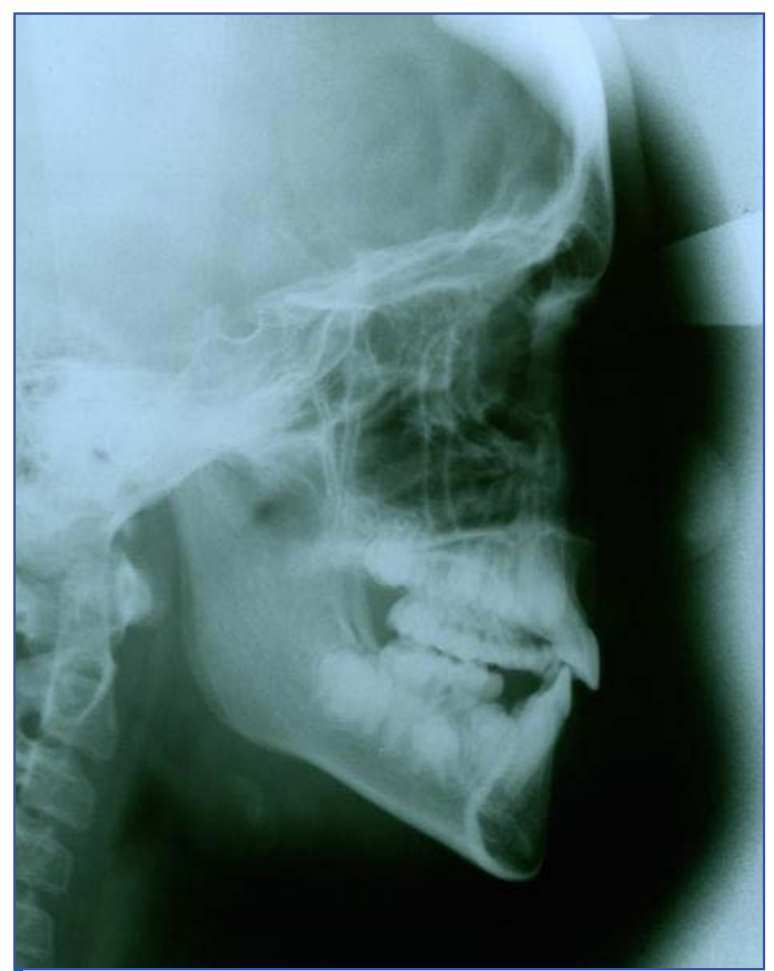

Figure 8. Posttreatment cephalometric of the same patient with tongue plate.

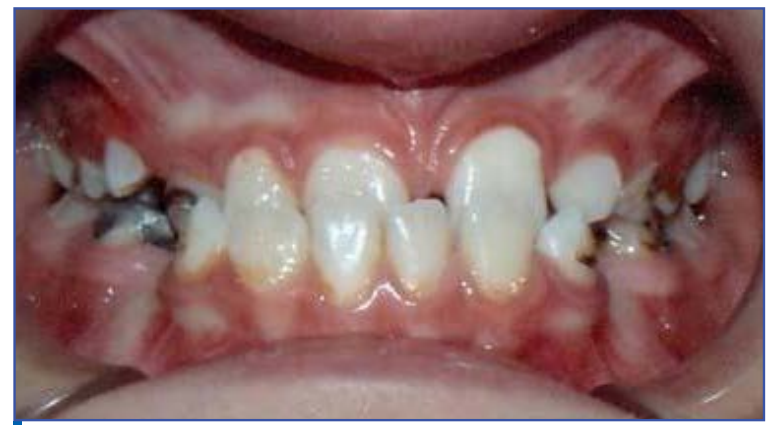

Figure 9. Frontal view of pretreatment of a tongue appliance patient.

after a two-week interval. A paired t-test showed no statistically significant differences between the two measurements.

An intraclass correlation coefficient was also calculated to assess test/retest reliability. The level

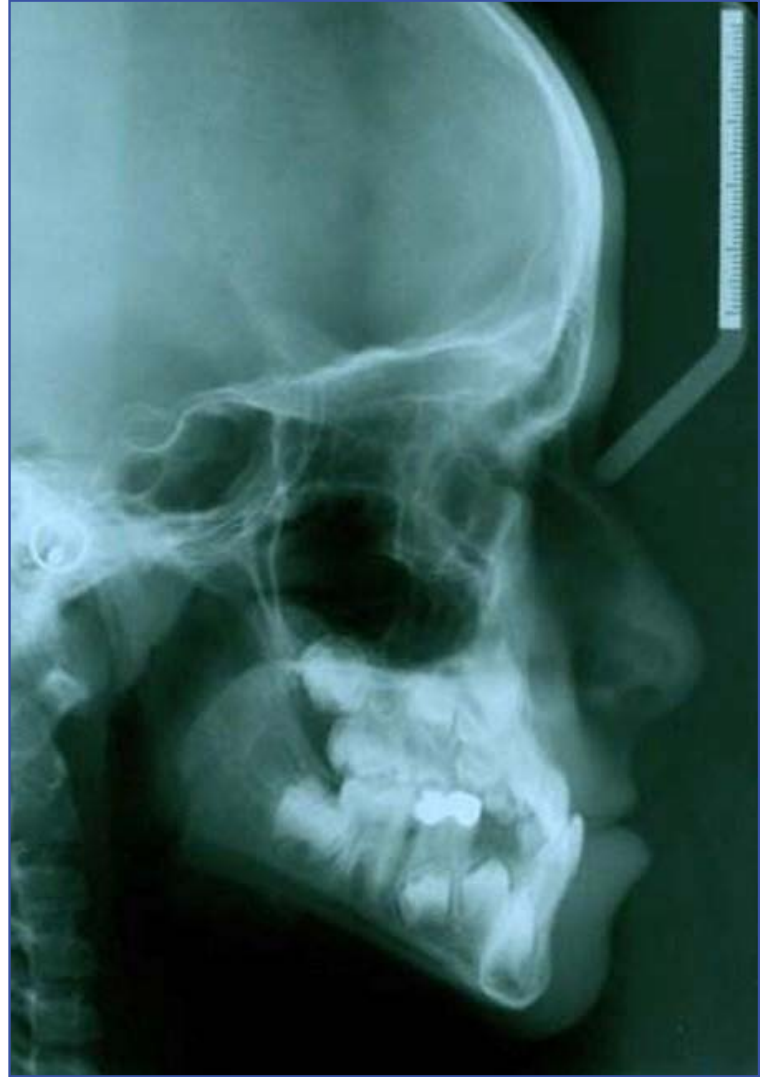

Figure 10. Pretreatment cephalometric of a patient with tongue appliance.

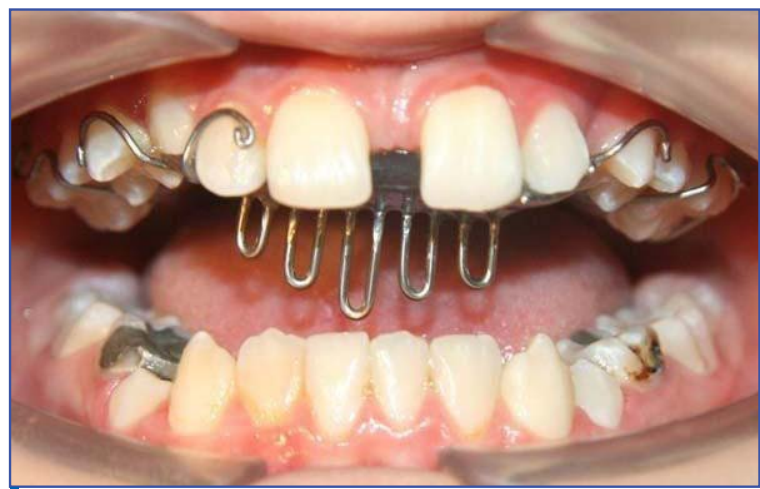

Figure 11. Frontal view of the tongue appliance.

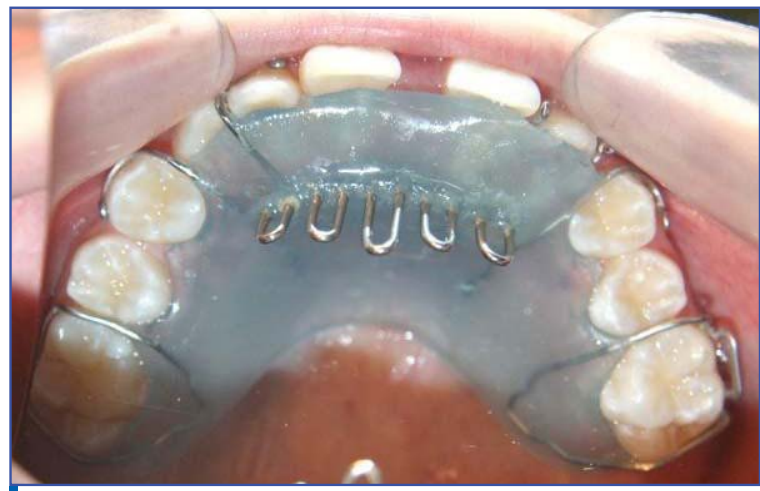

Figure 12. Palatal view of the tongue appliance.

of statistical significance was set at $p<05$. Paired T-tests were used for intra group evaluation if the distribution was normal; otherwise, the Wilcoxon test was used. The Mann-Whitney test was used to compare the data between the two groups. 


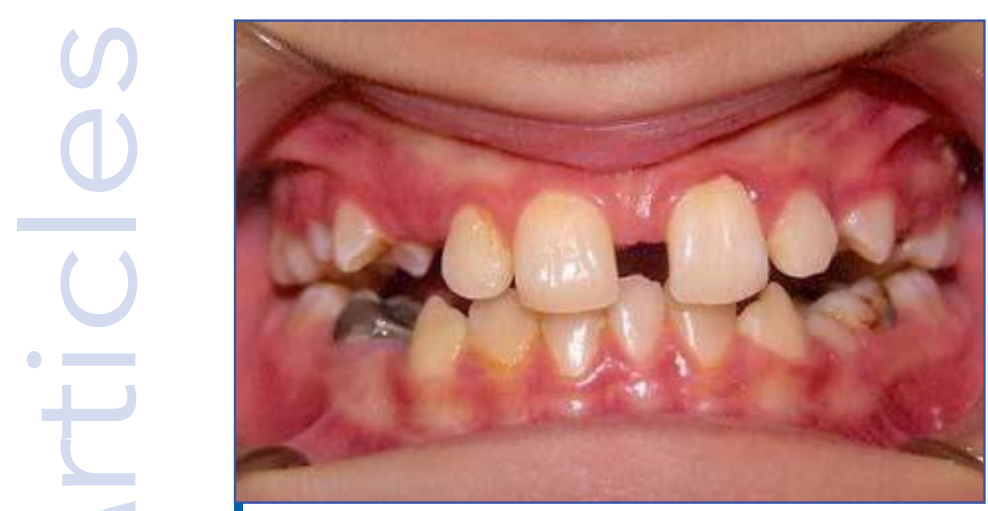

Figure 13. Frontal view of posttreatment of the same tongue appliance patient.

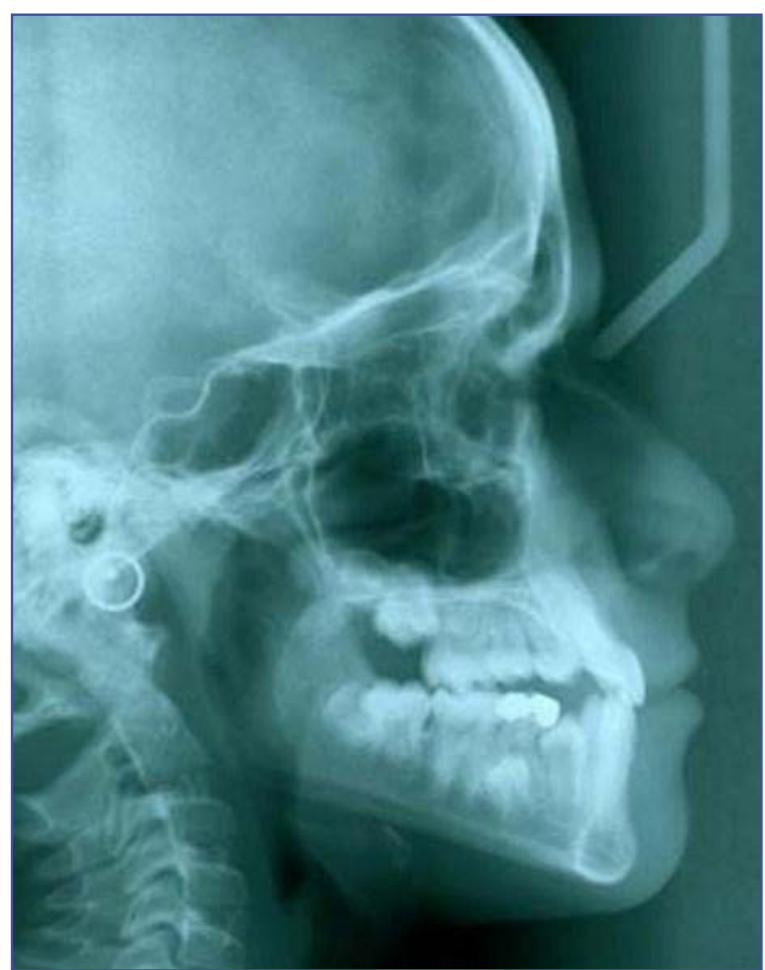

Figure 14. Pretreatment cephalometric of the same patient with tongue appliance.

\section{RESULTS}

The results of this study showed that SNA and ANB increased by $2.4 \pm 1.5^{\circ}(p<0.001)$ and $1.6 \pm 1^{\circ}(p<0.001)$ in the tongue plate group. SNA and ANB also increased in the tongue appliance group by $1.5 \pm 1.4^{\circ}$ $(p<0.001)$ and $1.6 \pm 1.6^{\circ}(p<0.001)$, respectively. The SNB did not show any significant changes in either of the groups. U1 to $\mathrm{SN}$ increased from $99.9 \pm 6.1^{\circ}$ to $103.7 \pm 5.3^{\circ}$ in the tongue plate group $(p<0.02)$ and it increased from $98.6 \pm 6^{\circ}$ to $99.9 \pm 7.2^{\circ}$ in the tongue appliance group $(\mathrm{p}<0.3)$.

The Mann-Whitney test showed that there were no statistically significant differences between the cephalometric data of the two groups; except for the Jarabak ratio. The Jarabak ratio decreased by $-0.4 \pm 1.6$ in the tongue plate group; yet, it increased by $0.6 \pm 3.2$ in the tongue appliance group $(p<0.03)$.

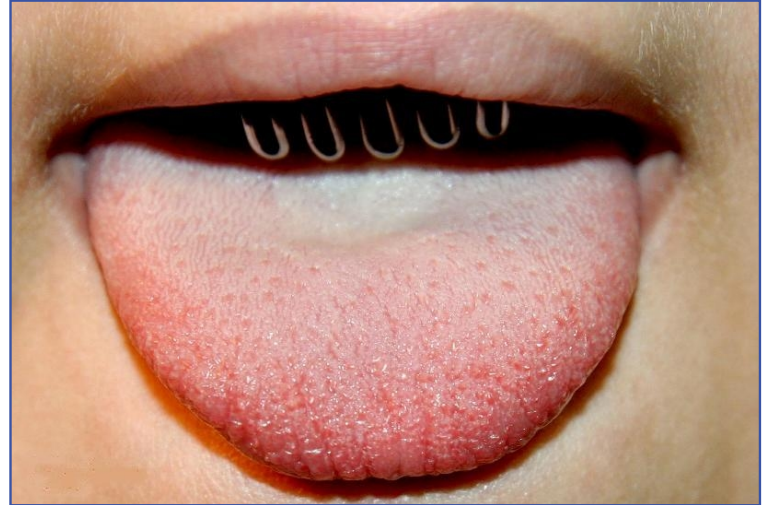

Figure 15. The mark of the tongue appliance on the tongue.

\section{DISCUSSION}

Various techniques and appliances are being used to treat the maxillary deficiency including modified protraction appliance, reverse-pull headgear, facemask, Class III activator, and reverse chin cup [7,8,24-35]. The face mask therapy has become a common technique used to correct the developing Class III malocclusion [36,37]. A search in literature will reveal ample research about the face masks and their effects on the nasomaxillary complex. In addition, the experimental studies constantly demonstrate pronounced forward movement of the maxilla due to the heavy and continuous protraction forces of the face masks [38-40]. However, one of the problems with the face masks is their bulky size and shape, which makes it a discouraging choice for children. Especially patients who wear glasses will be more susceptible to discomfort. This discomfort along with the embarrassment caused by the large size for children, especially at school in front of other peers, might reduce patient compliance. The chin part of the face mask will result in the backward rotation of the mandible and increase in the anterior facial height. Recently, tongue plate and tongue appliance were used to overcome the abovementioned disadvantages. In both appliances a considerable pressure will be transmitted to the deficient maxilla. The mechanism of the force is provided in the following ways:

1. The pressure of the Tongue during swallowing might reach 5 pounds in each swallowing. The frequency of swallowing is about 500 to 1200 times in 24 hours. This intermittent force is transferred through the tongue appliance to the deficient nasomaxillary complex.

2. The tongue generates a considerable force in its rest position while caged behind the cribs or plate. These forces are transmitted by the tongue to the palatal cribs or plate and finally to the nasomaxillary complex consequently pushing the maxilla to a forward position. The more anterior function and position of the tongue, the greater the force will be. The more posterior the crib or plate, the greater the force will be. The application of face masks might cause unfavorable effects on the mandible. 
In other words, backward and downward rotation of the mandible is one of the unfavorable effects of such extra oral appliances. These effects are very unsatisfactory in vertically growing patients. However, the tongue appliance and tongue plate used in this study had no adverse effects on the mandible. Another advantage of the tongue appliance and tongue plate over the other extra oral appliances is that it is less conspicuous and needs less patient compliance. The tongue appliance, tongue plate and facemask lingualize the lower incisors by different mechanisms. The tongue appliance and tongue plate lingualize the lower incisors due to the elimination of the tongue pressure on them. However, the facemask lingualizes the lower incisors due to chin cup pressure. The neutral zone is the area where the displacing forces of the lips and tongue are in balance. The presence of the tongue appliance and tongue plate in the mouth alters the neutral zone. In other words, since the tongue is caged by the crib or plate it does not exert any forces on the lower incisors thus, they are retroclined due to the pressure of the lips. After the appliances are removed, the tongue pressure on the lower incisors will result in their proclination. The force of the tongue transfers to the nasomaxillary complex and that is why the inclination angle is increased in both groups. In this study, both appliances were successful in forward movement of the maxilla. One of the advantages of the tongue plate is that unlike the tongue appliance it does not leave any marks on the tongue of the patient. The tongue appliance might bother the tongue and consequently parents are complaining about minor inflammation of the tongue. As can be seen in Fig. 15, the tongue appliance has left marks on the patient's tongue. It seems that the cooperation of the patient with the tongue plate is better than with the tongue appliance due to the smooth surface area of the tongue plate and lack of irritation of the cribs.

The treatment used in this study was meant to correct a skeletal problem as part of growth modification and further treatment was done by using fixed appliances.

\section{CONCLUSION}

Both treatment modalities were successful in moving the maxilla forward. The crib of the tongue appliance might bother the tongue and consequently parents are complaining about minor inflammation of the tongue. The smooth surface of the tongue plate might therefore confer some advantages to this system as compared to the tongue plate.

\section{CONFLICT OF INTEREST}

The authors declare no conflict of interest.

\section{AUTHOR CONTRIBUTIONS}

AJ: was responsible for the study concept, study design, data interpretation, critical revision, writing and revising the report and final approval of the article. LN: administration, data interpretation, recruitment, statistical analysis. EA: was responsible for data gathering. MT: was responsible for data interpretation, critical revision and final approval of the article. SB: was responsible for literature review. FF: was responsible for drafting, data interpretation, critical revision and final approval of the article.

\section{ACKNOWLEDGMENTS}

None.

\section{REFERENCES}

1. Ellis E 3rd, McNamara JA Jr. Components of adult Class III open-bite malocclusion. Am J Orthod. 1984;86(4):277-290. doi: 10.1016/0002-9416(84)90138-6.

Full Text Link PubMed GoogleScholar Scopus CrossRef WoS 2. Delaire J, Verdon P, Lumineau JP, et al. [Some results of extraoral tractions with front-chin rest in the orthodontic treatment of class 3 maxillomandibular malformations and of bony sequelae of cleft lip and palate]. Rev Stomatol Chir Maxillofac. 1972;73(8):633-642. PMID: 4514929.

PubMed GoogleScholar Scopus

3. Wells AP, Sarver DM, Proffit WR. Long-term efficacy of reverse pull headgear therapy. Angle Orthod. 2006;76(6):915-922. doi: 10.2319/091605-328.

Full-text link PubMed GoogleScholar Scopus CrossRef WoS 4. Jackson DW. The profile enhancer (reverse-pull headgear). Int J Orthod Milwaukee. 2009·20(3):21-25. PMID: 19835183.

PubMed GoogleScholar Scopus

5. Kokich VG, Shapiro PA, Oswald R, et al. Ankylosed teeth as abutments for maxillary protraction: a case report. Am J Orthod. 1985;88(4):303-307. doi: 10.1016/0002-9416(85)90129-0. PubMed GoogleScholar Scopus CrossRef WoS

6. Da Silva Filho OG, Ozawa TO, Okada CH, et al. Intentional ankylosis of deciduous canines to reinforce maxillary protraction. J Clin Orthod. 2003;37(6):315-320. PMID: 12866213.

PubMed GoogleScholar Scopus
7. Jamilian A, Showkatbakhsh R, Boushehry MB. The effect of tongue appliance on the nasomaxillary complex in growing cleft lip and palate patients. J Indian Soc Pedod Prev Dent. 2006;24(3):136-139. doi: 10.4103/0970-4388.27893.

PubMed GoogleScholar Scopus CrossRef

8. Jamilian A, Showkatbakhsh R. The effect of tongue appliance on the maxilla in Class III malocclusion due to maxillary deficiency. Int J Orthod Milwaukee. 2009;20(3):11-14. PMID: 19835181.

PubMed GoogleScholar Scopus

9. Showkatbakhsh R, Jamilian A, Behnaz M, et al. The short-term effects of face mask and fixed tongue appliance on maxillary deficiency in growing patients--a randomized clinical trial. Int $J$ Orthod Milwaukee. 2015;26(1):33-38. PMID: 25881382.

Full Text Link PubMed GoogleScholar Scopus

10. Showkatbakhsh R, Jamilian A, Ghassemi M, et al. Maxillary deficiency treatment by fixed tongue appliance--a case report. Int J Orthod Milwaukee. 2013;24(3):31-34. PMID: 24358655.

Full Text Link PubMed GoogleScholar Scopus

11. Showkatbakhsh R, Jamilian A. A novel method of maxillary deficiency treatment by tongue plate - a case report. Int J Orthod Milwaukee. 2011 2011;22(1):31-34. PMID: 21561019.

Full Text Link PubMed GoogleScholar Scopus

12. Showkatbakhsh R, Toumarian L, Jamilian A, et al. The effects of face mask and tongue plate on maxillary deficiency in growing 
patients: a randomized clinical trial. J Orthod. 2013;40(2):130-136. doi: 10.1179/1465313312Y.0000000036.

Full Text Link PubMed GoogleScholar Scopus CrossRef 13. De Clerck HJ, Cornelis MA, Cevidanes LH, et al. Orthopedic traction of the maxilla with miniplates: a new perspective for treatment of midface deficiency. J Oral Maxillofac Surg. 2009;67(10):2123-2129. doi: 10.1016/j.joms.2009.03.007. Full Text Link PubMed GoogleScholar Scopus CrossRef WoS 14. Showkatbakhsh R, Jamilian A, Behnaz M. Treatment of maxillary deficiency by miniplates: a case report. ISRN Surgery. 2011:854924. doi: 10.5402/2011/854924.

Full Text Link PubMed GoogleScholar CrossRef

15. Baccetti T, De Clerck HJ, Cevidanes LH, Franchi L. Morphomtric analysis of treatment effects of bone-anchored maxillary protraction in growing Class III patients. Eur J Orthod. 2011;33(2):121-125. doi: 10.1093/ejo/cjq170.

Full Text Link PubMed GoogleScholar Scopus CrossRef WoS 16. De Clerck EE, Swennen GR. Success rate of miniplate anchorage for bone anchored maxillary protraction. Angle Orthod. 2011;81(6):1010-1013. doi: 10.2319/012311-47.1. Full Text Link PubMed GoogleScholar Scopus Cross Ref WoS 17. Cevidanes L, Baccetti T, Franchi $L$, et al. Comparison of two protocols for maxillary protraction: bone anchors versus face mask with rapid maxillary expansion. Angle Orthod. 2010;80(5):799-806. doi: 10.2319/111709-651.1.

Full Text Link PubMed GoogleScholar Scopus CrossRef WoS 18. Jamilian A, Showkatbakhsh R. Treatment of maxillary deficiency by miniscrew implants - a case report. J Orthod. 2010;37(1):56-61. doi: 10.1179/14653121042876.

Full Text Link PubMed GoogleScholar Scopus CrossRef 19. Jamilian A, Haraji A, Showkatbakhsh R, Valaee N. The effects of miniscrew with Class III traction in growing patients with maxillary deficiency. Int J Orthod Milwaukee. 2011;22(1):25-30. PMID: 21827052.

Full Text Link PubMed GoogleScholar Scopus 20. Proffit WR, Fields HW, Sarver DM. Orthodontic Treatment Planning: Limitations, Controversies, and Special Problems. In: Proffit WR, Fields HW, Sarver DM, editors. Contemporary orthodontics. 4th ed. St. Louis, Mo.: Mosby Elsevier; 2007. p. 268327

21. Ramadan AA. Response of maxillary retrusion cases to face mask treatment. World J Orthod. 2008;9(2):e29-34. PMID: 19641766.

Full Text Link PubMed GoogleScholar Scopus

22. Yavuz I, Halicioglu K, Ceylan I. Face mask therapy effects in two skeletal maturation groups of female subjects with skeletal Class III malocclusions. Angle Orthod. 2009;79(5):842-848. doi: 10.2319/090308-462.1.

Full Text Link PubMed GoogleScholar Scopus CrossRef WoS 23. Godt A, Zeyher C, Schatz-Maier D, Göz G. Early treatment to correct Class III relations with or without face masks. Angle Orthod. 2008;78(1):44-49. doi: 10.2319/110606-455.1.

PubMed GoogleScholar Scopus CrossRef

24. Kajiyama K, Murakami T, Suzuki A. Evaluation of the modified maxillary protractor applied to Class III malocclusion with retruded maxilla in early mixed dentition. Am J Orthod Dentofacial Orthop. 2000;118(5):549-559. doi: 10.1067/ mod.2000.110169.

PubMed GoogleScholar Scopus CrossRef WoS

25. Satravaha S, Taweesedt N. Stability of skeletal changes after activator treatment of patients with class III malocclusions. Am J Orthod Dentofacial Orthop. 1999;116(2):196-206. doi: 10.1016/ s0889-5406(99)70218-0.

PubMed GoogleScholar CrossRef Scopus WoS

26. Orton HS, Noar JH, Smith AJ. The customized facemask. J Clin Orthod. 1992;26(4):230-5. PMID: 1452725

PubMed GoogleScholar Scopus

27. Suda N, Ishii-Suzuki M, Hirose K, et al. Effective treatment plan for maxillary protraction: is the bone age useful to determine the treatment plan? Am J Orthod Dentofacial Orthop. 2000;118(1):5562. doi: $10.1067 / \bmod .2000 .104491$.

PubMed GoogleScholar CrossRef

28. Showkatbakhsh $\mathrm{R}$, Jamilian A. A novel approach in treatment of maxillary deficiency by reverse chin cup. Int J Orthod Milwaukee. 2010;21(2):27-31. PMID: 20687313.

Full Text Link PubMed GoogleScholar Scopus
29. Jamilian A, Cannavale R, Piancino MG, et al. Methodological quality and outcome of systematic reviews reporting on orthopaedic treatment for class III malocclusion: Overview of systematic reviews. J Orthod. 2016;43(2):102-120. doi: 10.1080/14653125.2016.1155334.

Full Text Link PubMed GoogleScholar Scopus CrossRef WoS 30. Eslami S, Faber J, Fateh A, et al. Treatment decision in adult patients with class III malocclusion: surgery versus orthodontics. Prog Orthod. 2018;19(1):28. doi: 10.1186/s40510-018-0218-0. Full Text Link PubMed GoogleScholar Scopus CrossRef WoS 31. Showkatbakhsh R, Jamilian A, Taban T, Golrokh M. The effects of face mask and tongue appliance on maxillary deficiency in growing patients: a randomized clinical trial. Prog Orthod. 2012;13(3):266-272. doi: 10.1016/j.pio.2011.12.004.

Full Text Link PubMed GoogleScholar Scopus CrossRef 32. Showkatbakhsh R, Jamilian A, Ghassemi M, et al. The effects of facemask and reverse chin cup on maxillary deficient patients. J Orthod. 2012;39(2):95-101. doi: 10.1179/1465312512Z.000000 00011.

Full Text Link PubMed GoogleScholar CrossRef 33. Jamilian A, Showkatbakhsh R, Taban T. The effects of fixed and removable face masks on maxillary deficiencies in growing patients. Orthodontics (Chic.). 2012;13(1):e37-43. PMID: 22567652. PubMed GoogleScholar

34. Showkatbakhsh $R$, Jamilian A, Behnaz M. Treatment of maxillary deficiency by miniplates: a case report. ISRN Surg. 2011;2011:854924. doi: 10.5402/2011/854924.

Full Text Link PubMed GoogleScholar CrossRef

35. Perillo L, Vitale M, Masucci C, et al. Comparisons of two protocols for the early treatment of Class III dentoskeletal disharmony. Eur J Orthod. 2016;38(1):51-56. doi: 10.1093/ejo/ cjv010.

Full Text Link PubMed GoogleScholar Scopus CrossRef WoS 36. Jamilian A, Nucci L, Fateh A, et al. Stability of skeletal Class III malocclusion after orthognathic surgery and orthodontic treatment: a systematic review and meta-analysis. Stoma Edu J. 2020;7(1):52-67.

Full Text Link GoogleScholar CrossRef

37. Jamilian A, Darnahal A, Nucci L, et al. Treatment considerations for missing teeth. Dental Anatomy. Rijeka: Intech; 2018. p. 109-120. CrossRef

38. Cha KS. Skeletal changes of maxillary protraction in patients exhibiting skeletal class III malocclusion: a comparison of three skeletal maturation groups. Angle Orthod. 2003;73(1):26-35. doi: 10.1043/0003-3219(2003)073<0026:SCOMPI> 2.0.CO;2.

PubMed GoogleScholar Scopus WoS

39. Maspero C, Galbiati G, Perillo L, et al. Orthopaedic treatment efficiency in skeletal Class III malocclusions in young patients:

RME-face mask versus TSME. Eur J Paediatr Dent. 2012;13(3):225230. PMID: 22971261

Full Text Link PubMed GoogleScholar Scopus WoS 40. Dellinger EL. A preliminary study of anterior maxillary displacement. Am J Orthod. 1973;63(5):509-516. doi:

10.1016/0002-9416(73)90163-2.

PubMed GoogleScholar Scopus CrossRef

41. Nanda R. Protraction of maxilla in rhesus monkeys by controlled extraoral forces. Am J Orthod. 1978;74(2):121-141. doi: 10.1016/0002-9416(78)90080-5.

PubMed GoogleScholar Scopus CrossRef

42. Kambara T. Dentofacial changes produced by extraoral forward force in the Macaca irus. $A m \mathrm{~J}$

Orthod.1977;71(3):249-277. doi: 10.1016/0002-9416(77)90187-7.

PubMed GoogleScholar Scopus CrossRef

43. Marra P, Nucci L, Abdolreza J, et al. Odontoma in a young and anxious patient associated with unerupted permanent mandibular cuspid: A case report. J Int Oral Health 2020;12(2):182-186. doi: 10.4103/jioh.jioh_287_19.

GoogleScholar Scopus CrossRef

44. Minervini G, Nucci L, Lanza A, et al. Temporomandibular disc displacement with reduction treated with anterior repositioning splint: a 2-year clinical and magnetic resonance imaging (MRI) follow-up. J Biol Regul Homeost Agents. 2020;34(1 Suppl. 1):151160. PMID: 32064850.

PubMed GoogleScholar Scopus 


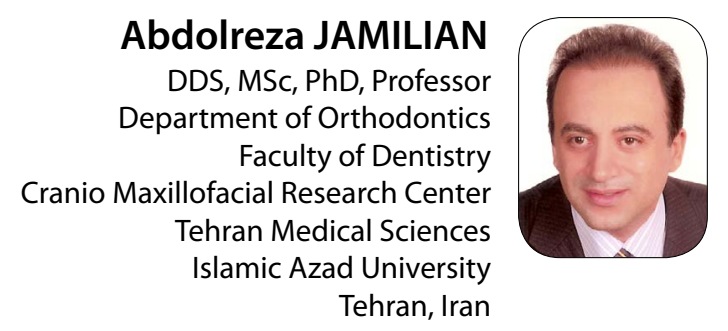

Professor Abdolreza Jamilian is an Orthodontic researcher and specialist. He received his DDS (1991), MSc in Orthodontics (1998), and Fellowship of Orthognathic Surgery \& Craniofacial Syndroms (2010) from the Shahid Beheshti University in Tehran, Iran. He obtained his European Board of Orthodontics in 2013. He is a professor at the Islamic Azad University, Tehran. He practices in orthodontics. He has lectured in several international congresses and has been a consultant for various journals. He has published over 200 original, peer reviewed research and review articles, 15 book chapters and more than 300 scientific communications. He holds 3 patents with the United States Patent and Trademark Office.

Research interests: Class 3 malocclusion, Cleft lip and palate, Orthognathic surgery.

\section{Ouestions}

\section{Which one has been used to treat maxillary deficiency?}

a. Fixed tongue appliance;

ab. Tongue plate;

ac. Tongue appliance;

d. All of them.

\section{Which one is an extra oral appliance?}

口a. Reverse chin cup;

$\square$ b. Tongue appliance;

$\square$ c. Fixed tongue appliance;

ad. Tongue plate.

\section{Which one does the patient wear easily during daily activities?}

a. Reverse chin cup;

ab. Tongue plate;

$\square c$. Face mask;

ad. Chin cap.

\section{Which one has no effect on the patients' vertical growth pattern?}
Da. Face mask;
ab. Chin cap;
ac. Reverse chin cup;
ad. Tongue plate. 